\title{
Measuring household food security: the global experience
}

\author{
A medida da segurança alimentar: \\ a experiência mundial
}

Hugo MELGAR-QUINONEZ1

Michelle HACKETT ${ }^{1}$

Measuring household food insecurity represents a challenge due to the complexity and wide array of factors associated with this phenomenon. For over one decade, researchers and agencies throughout the world have been using and assessing the validity of variations of the United States Department of Agriculture Household Food Security Supplemental Module. Thanks to numerous studies of diverse design, size, and purpose, the Household Food Security Supplemental Module has shown its suitability to directly evaluate the perceptions of individuals on their food security status. In addition, challenges and limitations are becoming clearer and new research questions are emerging as the process advances. The purpose of this article is to describe the development, validation procedures, and use of the Household Food Security Supplemental Module in very diverse settings. The most common Household Food Security Supplemental Module related studies have been conducted using criterion validity, Rasch modeling and Cronbach-Alpha Coefficient. It is critical that researchers, policy makers, governmental and non-governmental agencies intensify their efforts to further develop tools that provide valid and reliable measures of food security in diverse population groups. Additional work is needed to synthesize a universally applicable tool able to capture the global human phenomenon of food insecurity.

Indexing terms: Measures. Food security. Validity of tests.

\section{RE S U M O}

M edir a insegurança alimentar domiciliar representa um desafio devido à complexidade e ao vasto número de fatores associados a este fenômeno. Por mais de uma década, pesquisadores e agências em todo o mundo têm usado o Módulo Suplementar da Segurança Alimentar Domiciliar, do Departamento de Agricultura dos Estados Unidos (Household Food Security Supplemental M odule), e avaliado suas variações. Graças a numerosos estudos com diversos formatos, extensões e propósitos, a adequação do Household Food Security Supplemental Module para avaliar diretamente a percepção dos indivíduos acerca de seu estado de segurança alimentar

\footnotetext{
${ }^{1}$ Ohio State University, Department of Human Nutrition. 1787 N eil Avenue Columbus, OH 43210. Correspondence to/Correspondência para: H.R. MELGAR-QUINONEZ. E-mail: «melgar-quinonez.1@osu.edu>.
} 
pôde ser comprovada. Além disso, as limitações desse módulo e os desafios que os pesquisadores ainda precisam enfrentar vêm se tornando mais claros, e novas questões a serem pesquisadas vêm surgindo à medida que o processo avança. O objetivo deste artigo é descrever o desenvolvimento, os procedimentos de validação e o uso do Household Food Security Supplemental Module em cenários distintos. A maioria dos estudos sobre o Household Food Security Supplemental Module foi efetuado usando critérios de validação, o modelo de Rasch e o Coeficiente Alfa de Cronbach Alfa. É vital que os pesquisadores, os responsáveis pela determinação de políticas públicas e as agências governamentais e não governamentais intensifiquem seus esforços para desenvolver novas ferramentas que forneçam medidas válidas e confiáveis de segurança alimentar em diferentes grupos populacionais. É necessário um esforço adicional para sintetizar uma ferramenta universalmente aplicável, que seja capaz de capturar o fenômeno humano global da insegurança alimentar.

Termos de indexação: Medidas. Segurança alimentar e nutricional. Validade dos testes.

\section{IN TRO D U C TIO N}

The lack of access to a sufficient food supply that allows people to meet their nutritional requirements for an active and healthy life has long been a concern of world leaders, as evidenced by the Universal Declaration of Human Rights from 1948: "Everyone has the right to a standard of living adequate for the health and well-being of himself and of his family, including food..." (Article 25 of the Universal Declaration of Human Rights; Adopted and proclaimed by General Assembly of the United Nations resolution 217 A (III) of 10 December 1948). M ore than half a century later though, the most recent figures on food insecurity and hunger by the United Nations' Food and Agriculture Organization estimate that, worldwide, about 850 million people do not have enough to eat ${ }^{1}$. Regardless of a decrease in the number of hungry people in developing countries by 37 million during the first half of the 1990s, in the second half of the decade hunger estimates have shown an increase in several regions of the developing world. At the 1996 World Food Summit representatives from many different countries reaffirmed that it is a fundamental right for inhabitants throughout the world to have access to adequate, safe and nutritious food ${ }^{1}$. It is well recognized by governments and international agencies that food insecurity not only increases the risk for malnutrition and illness, but also exacerbates conflict and political instability. Therefore, improvements in the availability and access of food not only benefit individuals, but also the communities and countries in which they live.

As a crucial component of efforts in overcoming food insecurity and hunger, development organizations and governments need to establish effective and reliable monitoring and evaluation systems in order to establish which interventions have a positive impact in the food security status of their populations, and when changes are required to improve the application of policies and programs. Typically, economic indicators of food production and food availability have been used to assess food security at national and regional levels. Unfortunately, these methods, besides being very expensive, do not provide information reflecting the access by poor households to available food supplies. Therefore, the need for food security measures that provide data at the household level has been long identified by both national and international agencies. In order to be applicable on a regular basis through community-based networks, household food security measurements need to be easy to apply, inexpensive, easy to evaluate, and closely reflect the actual situation at home and community levels. In the mid 90's, the United States Department of Agriculture developed a Household Food Security Supplemental Module (HFSSM ) that takes into consideration the overall household experience and divides it into several categories of food insecurity ${ }^{2}$. Profuse research studies have confirmed the validity of HFSSM as an inexpensive and easy to use and analyze method for measuring household food insecurity in different populations living in the US ${ }^{3-5}$. 
Recently, several efforts are being conducted in other countries to exhaustively test similar tools to measure household food insecurity for validity and reliability. In Latin America, the HFSSM and similar tools have successfully tested in the studies conducted ${ }^{6-9}$. In Brazil and Colombia, where locally adapted tools were recently tested, the current research includes data on nationally representative population samples as an effort to develop nationwide suitable tools $\mathbf{s}^{8,9}$. Additionally in the Caribbean, studies have also shown the usefulness of such instruments ${ }^{10}$. Outside the Americas, adapted versions of the HFSSM have been used in the context of emergency situations or humanitarian relief operations ${ }^{11,12}$. In addition to the use of locally adapted and modified HFSSM surveys, specific tools have been developed taking into account the local experiences and coping strategies to confront the phenomenon of food insecurity ${ }^{13-15}$.

\section{Why measure household food insecurity?}

Despite the recognized high prevalence of food insecurity in the developing world, there is still uncertainty regarding the exact number of individuals who are not food secure and to what degree they are affected. The measurement of food insecurity and its causes and consequences is a critical aspect in addressing the problem because it allows for the estimation of prevalence, the identification of causes, a better targeting of high risk population groups, and the establishment of reliable monitoring and evaluation systems of national food programs ${ }^{3}$.

During the World Food Summit five methods were discussed to decrease the number of hungry people by $50 \%$ before 2015: 1) Combining information from food balance sheets and household income and expenditure surveys; 2) Measuring food insecurity using household income and expenditure survey data; 3) M easuring adequacy of dietary intake based on individual intake surveys; 4) M easuring child nutritional status based on anthropometric surveys; and 5) Qualitative methods for measuring people's perception of food insecurity. Although the first four quantitative measures are fairly comprehensive, they are also expensive and time consuming. They also do not take into consideration the experience of food insecurity, which also includes social and psychological stress associated with not having the enough food ${ }^{1}$. There are a number of factors determining the level of food insecurity at the household level, like mother's education level, household size, age, and race/ethnic group ${ }^{16}$. Large households, especially those headed by a single parent, are more likely to be food insecure ${ }^{17,18}$.

Based on a food security definition that includes the access at all times by all people to adequate amounts of safe, nutritious and culturally acceptable food for an active and healthy life $\mathrm{e}^{19}$, its concept includes the following main components: 1) Sufficient quantity of food consumed; 2) Sufficient quality of food- diversity, safety and familiarity; 3) Security and predictability of acquisition; 4) Acceptability, or staying within the normal bounds of society for acquisition; and 5) Food security for all individuals of the household regardless of age or gender ${ }^{20}$.

\section{Household food security supplemental module in the US}

In the United States (US), as early as 1984 the President's Task Force on Food Assistance reported hunger in the US but was unable to quantify the extent. In 1990, the National Nutrition Monitoring and Related Research Act was passed in order to standardize instruments for obtaining and defining data on the prevalence of food insecurity ${ }^{21}$. Initially, the Community Childhood Hunger Identification Project (CCHIP) based their conceptual framework on the Massachusetts Nutrition Survey (1983), which allowed researchers to define hunger as food insufficiency due to lack of resources. A hunger index was developed with eight questions about household food resources, 
insufficient food intake for adults, and insufficient food intake for children in the home ${ }^{22}$. Later, Radimer developed a series of open ended questions that were asked to low-income women on their perceptions of food insecurity. From their responses a survey was developed that was made up of their statements. Based on these experiences in 1992, a food security measurement was developed for the US. The current US Household Food Security Supplemental Module (HFSSM) is made up of 18 questions and categorizes the surveyed households into two main categories: food secure and food insecure households. Since 2005, the latter is further divided into two groups: households with low food security and households with very low food security, which have replaced the labels "food insecurity without hunger" and "food insecurity with hunger", used previously ${ }^{23}$. Since children are typically the last to feel the effects of food insecurity because the parents sacrifice their own meals for them ${ }^{24}$, the last category includes the most severe level of food insecurity (or low food security) where this situation is evident among children.

\section{Validity of the HFSSM in the US}

Intense testing of the HFSSM has confirmed the conceptual framework and ability to measure food security in the US ${ }^{3}$. Additional research has demonstrated the validity and reliability of this tool in minority groups like Asian and Pacific Islanders in Hawaii and Latinos in California. The HFSSM has shown its ability to address the availability of nutritionally adequate food, although certain aspects were not entirely valid with subgroups of Samoans, suggesting that the instrument is not necessarily appropriate with all racial/ethnic groups ${ }^{4}$. Researchers in California found that preschool children in families with lower food security were less likely to meet the Food Guide Pyramid guidelines ${ }^{5}$. Food insecurity as measured by the HFSSM includes shortages of food, unsuitability of food and the preoccupation with continuing access to food ${ }^{25}$. Low female education level and large families are also associated with increased hunger, both of which are prevalent in Latino families ${ }^{26}$. Food insecurity is initially characterized by decreased amounts and varieties of food. Fruits and vegetables are among the first food groups to be eliminated when money is short ${ }^{27,28}$. Food insecure households generally consume less meat and milk, which is directly related to payday ${ }^{29}$. Individuals suffering from food insecurity also reported more multiple chronic diseases, depression and distress ${ }^{30}$.

The multiple uses of tools based on the HFSSM, or developed using similar approaches, will be below listed by geographical area, stating with Latin America and the Caribbean, where its application has already national dimensions. The several research projects and applications presented in this review approach evaluate the usefulness of the food security measurement scales through its correlations with other factors closely associated with the underlying phenomenon, using mainly the following: dietary intake, expenses on food, income, educational level, health conditions. In addition, some research groups have been able to compare measurements among population groups within countries: rural and urban populations, male and female respondents, etc.

\section{Household food security measurement in Latin America and the Caribbean}

Currently, evidence starts to accumulate in the scientific literature regarding the validity of the HFSSM outside the United States. The first published studies on a tool similar to the HFSSM were carried out in Venezuela ${ }^{6}$ revealing that assessment of predictors of energy availability and self-perceived household food security may be a reliable way to identify and monitor food security in peri-urban homes.

In 2002, as part of the larger study PLAN (Planificación Local de la Agricultura y la Naturaleza- Community Planning for Sustainable Livestock-based Forested Ecosystems), a qualitative assessment of the food security status 
was conducted in several rural communities located in Bolivia, Ecuador and M exico ${ }^{31}$. Through focus groups, daily dietary reports, and in-depth interviews this study addressed the local concept of food insecurity, as well as the main causes and consequences as identified by the villagers. Sadness, desperation and anxiety because of the food deprivation and monotony were part of the local perception of hunger, as well as its impact on the health status of adults and children. The diet in the three countries mainly consisted of energy dense foods, with a very low consumption of fruits, vegetables and animal source foods. In a second phase of the study, a survey including an adapted version of the HFSSM was applied in both the Ecuadorian and M exican settings. In the sample of poor rural families in Ecuador, comparisons were made between food security score and household food inventory ${ }^{32}$. A significant inverse correlation was found between total inventory $(p<0.01)$ and food insecurity level. Food insecurity was also correlated with low food supply, such as meat $(p<0.01)$, grains $(p<0.05)$, and animal products $(p<0.05)$. Vegetables, fruit, processed food, sugars, fats, and treats consumption was also associated with level of food security $(p<.01)^{32}$. From these data it is apparent that food insecurity captures the conceptual framew ork of hunger and related aspects such as household food stores and money spent on food. In M exico, food insecurity was significantly and inversely correlated with the number of food items in the household ( $r=-0.36)$, animal source foods ( $r=-0.28)$, dairy products $(r=-0.25)$, processed foods $(r=0.37)$, fruits $(r=-0.21)$, and vegetables $(r=-0.28)^{7}$. Food insecurity was also associated with low dietary variety $(r=-0.23$, $p=0.02$ ). In M exico, using an urban sample in the capital city, Parás also found significant inverse correlations between the HFSSM measure and income, self-reported health status, and consumption of fruits, vegetables, meats and dairy product $^{33}$. By contrast, the consumption of the staple foods such as beans and tortillas was not associated with food insecurity as measured through the proposed tool.
In 2003 in Bolivia, as part of a study including three countries located in different continents, a statistical significant correlation was found between expenditure per capita per day and food security status measured by an adapted version of the HFSSM that excluded those items related to the children in the household ${ }^{34}$. Expenditure on food (animal source foods, cereals, fruits, vegetables, tubercles, legumes oils and fats) was significantly higher among those households classified as food secure when compared with food insecure households.

That same year, the World Bank reported the application of the HFSSM in a representative sample of Argentinean urban households, as part of a national survey conducted in 2002. This measurement showed significantly higher prevalences of food insecurity among households under the poverty line, households with children, and head of household with lower educational level, when compared with non-poor households, without children and respondents with university degrees ${ }^{35}$.

Also in 2003, Pérez-Escamilla et al. applied a modified Portuguese version of the HFSSM to a representative sample of households in the city of Campinas (SP), Brazil ${ }^{8}$. In this study the authors found significantly inverse correlations with daily intake of fruits, vegetables, meat/fish, and dairy. Later food insecurity perceptions were explored in households with elderly in the same region. Food insecure households reported lower income and education levels of the elderly. Those households also had lower intake of vegetables, meat and fruit ${ }^{36}$. Additionally to Brazil, Mexican researchers have been conducting research regarding the measurement of food insecurity in elderly living in Mexico City ${ }^{37}$.

As research showed the validity of the adapted HFSSM in Campinas (SP), the methodology used in it was replicated in several urban and/or rural areas throughout the country, resulting in the inclusion of the proposed instrument in nationally representative survey samples, which allowed estimating the prevalence of food security at the 
national level ${ }^{38}$. The study in Campinas (SP), has been accompanied by an in-depth exploration of the performance of the tool using Rasch modeling analysis with very encouraging results supporting the validity of this instrument ${ }^{39}$. Currently, Rasch modeling is being applied to national data to assess the validity of the Brazilian food security scale in different sub-population groups (urban/ rural; male/female respondent; households with and without children; by region, etc. $)^{39}$.

Parallel to the studies described above, researchers at the University of Antioquia in Medellín, Colombia, conducted a study with the purpose of adapting and validating the food security scale previously applied by Lorenzana in Caracas, Venezuela9 ${ }^{9}$. The study was carried out in a randomly selected sample of rural and urban households with children less than 10 years of age. Factor analysis of the resulting data showed that the scale discriminates at least two components: 1) food insecurity without hunger; and 2) food insecurity with hunger. When analyzed using Rasch modeling, all items showed infit values within a range of 0.8 and 1.2, which is considered adequate for this scale. The measurement showed highly significant associations with food availability, begging, children's labor, and household size. Based on the results of this study, the Colombian researchers proposed the inclusion of this tool in the Colombian National Health and Nutrition Survey (ENSIN 2005). As well as in a previous study conducted with national data from Brazil, Rasch modeling of Colombian data has shown good infit values, as well as a consistent order in the severity values of the items for female and male respondents, and urban and rural households ${ }^{40}$.

In the Caribbean islands of Trinidad and Tobago, researchers have evaluated the English version of the HFSSM for validity ${ }^{10}$. Adult and children items were divided and analyzed separately to determine calibrations using one parameter and two-parameter models to determine the fitness of data. Researchers concluded that a one-parameter model is generally sufficient to determine fitness of the HFSSM ${ }^{10}$. In
Trinidad and Tobago, food security was associated with monthly household income; as income increased food insecurity decreased ${ }^{41}$. In addition, a negative association was found between the educational level of mothers and food security status. After adjusting for income, Indo-Caribbean subjects were found to be more food insecure than their Afro-Caribbean counterparts ${ }^{41}$.

Studies developing, validating, and applying the HFSSM have been done on five continents spanning a wide range of cultures and societies. Two separate research groups in Canada explored food insecurity using the HFSSM. The first study consisted of low-income single mothers living in Atlantic Canada ${ }^{42}$. Researchers found that higher levels of household food insecurity were associated with older maternal age and smaller community size. In a sample of Toronto women seeking charitable food aid, HFSSM items were used with time frames of the past 12 months or 30 days $^{43}$. Food insecure households, as defined by HFSSM, consumed less grains, dairy, vegetable and fruits, and meat. Social isolation or activity limiting health conditions were more likely to be categorized as food insecure. The authors also proposed that financial insecurity is strongly associated with food insecurity.

\section{Experiences with HFSSM and similar tools outside the Americas}

In the early 1990's researchers working for the U.S. humanitarian relief organization CARE in the Russian Federation applied the HFSSM to mothers of children under the age of two. Researchers found comparable response patterns to New York women who responded to the HFSSM , although Russian women had higher rates of food insecurity ${ }^{12,44}$. Both samples answered affirmatively more often to questions regarding limitations in quality of food as opposed decreases in quantity of food. In addition, mothers from both continents protected their children from hunger. In Russia, the HFSSM showed significantly higher rates of food insecurity in households with the 
following characteristics: headed by single mothers, under the poverty line, $\geq 3$ children, rural households, non-Russian mother, primary breadwinner unemployed, and mother with lower educational level ${ }^{12}$.

After an economic crisis hit Indonesia in 1997-1998, health professionals and researchers in Java and Thailand quantified levels of food insecurity using the HFSSM in two separate studies $^{11,45}$. Thai researchers applied the model with poor household food providers in urban slums ${ }^{45}$. This population reported high levels of food insecurity, poor dietary intake, and low-income. In Java in-depth interviews were completed with mothers from a range of settings to establish face validity of the HFSSM ${ }^{11}$. From these conversations, cultural adaptations of the HFSSM were made and then applied to households throughout Java. The results exhibited similar affirmative response patterns when compared with studies in New York ${ }^{2}$ and Quebec ${ }^{46}$, demonstrating the relative severity of items was analogous for all three samples. Low levels of food expenditure, total expenditure, income, food stores, and rice stores were all associated with statistically significant higher levels of food security. In Bangladesh, researchers developed their own HFSSM based on in-depth interviews with rural women ${ }^{13}$. Four levels of food insecurity were distinguished (food secure, occasionally, moderately and extremely food insecure) and led to the 11 items that were included in the final tool. Resulting themes from the interviews in reference to quantity and quality of food were comparable to studies in New York, Quebec, and Java ${ }^{13}$.

In the neighboring islands of the Philippines, researchers explored the performance of a culturally adapted 9-item HFSSM version ${ }^{34}$. Household food score was associated with daily per capita food expenditure for all foods and the following groups: animal-source foods, dairy, eggs, meats, fish, cereals, vegetables, fruits, and oils and fats. In the Southwest Pacific Ocean, food insecurity was measured on the islands of Vanuatu ${ }^{47}$. Researchers used the HFFSM in the evaluation of a capacity building project in Maewo in comparison to the neighboring island of Ambae. In general, Maewo households had generally improved levels of food insecurity with a lower level of households experiencing moderate levels of hunger and higher levels of mild food insecurity. There were no statistically significant differences in the number of food secure or child food insecure households based on access to the capacity building project.

Under the Ministry of Health and Human Welfare in the Republic of Korea, researchers used the 10-item HFSSM to measure household food insecurity in low-income households with child in urban areas ${ }^{48}$. Food insecurity, as reported in the survey, was negatively associated with caretaker nutrition knowledge and household economic status. The measurement was also associated with children's dietary intake and body weight. Nutrient intakes were lower for households where adults experienced food insecurity and households with incidents of children hunger. Mild ly food insecure children were heavier than food secure, likely due to the consumption of inexpensive high calorie food intake.

In three different regions of Africa, researchers applied the HFSSM to better understand the situation of food insecurity. In Vaal Triangle, South Africa, the tool was administered to caregivers and children between the ages of 9-13 years old. The HFSSM was used in this population to determine the coping methods used by the households ${ }^{49}$. Descriptive statistics revealed that caregivers reported the following behaviors: limiting portion sizes (80.0\%), maternal buffering $(75.8 \%)$, limiting variety of foods served $(74.7 \%)$, and skipping meals $(68.4 \%)$. In rural Tanzania researchers examined the relationship between food insecurity and depression as measured by the Hopkins Symptom Checklist ${ }^{50}$. A positive correlation between food insecurity status and depression was shown when adjusting for caretaker's age and marital status. These results were universal for the four ethnic groups studied: Pimbwe, Sukuma, Iraqw, and Datoga. When 
researchers applied the HFSSM in Burkina Faso, correlations were analyzed between food security levels and daily per capita food expenditures ${ }^{34}$. Households at higher levels of food insecurity spent less money on total foods and the following food groups: animal-source foods, dairy, eggs, meats, tubercles, vegetables, and oils and fats. Researchers confirmed that the adapted HFSSM is appropriate for measuring food insecurity in poor countries of Africa. A separate research group developed and validated a food security survey from the ground-up based on focus groups in Burkina Faso ${ }^{14}$. As was done previously in the development of the Radimer/Cornell scale, themes of food insecurity were identified and food insecurity categories were created. This new tool was then applied in a longitudinal study in which food insecurity scores were validated based on seasonality, cross-sectional performance, and changes in household food insecurity ${ }^{14}$. Food insecurity as determined by the scale developed was statistically significantly associated with economic indicators of total assets and net income per adult. Another study with refugees disclosed that, the more food insecure individuals ate fewer meals, had lower adult weight and decreased BM I over specific time periods in the year ${ }^{14}$.

In the United Kingdom (UK) food insecurity levels were explored with two high risk populations: low income urban dwellers and refugee households. Income, university attainment, fruit and vegetable consumption were all found to be associated with results of the short 6-item HFSSM household food security level in low income urban households ${ }^{51}$. Food insecure households had lower income, education, and fruit and vegetable consumption. All Refugee families in East London (UK), exhibited food insecurity at various levels in $2001^{52}$. Severe food insecurity, as manifested by hunger experienced by children was statistically significantly associated with recent arrival to the country. It is important to note that mother education, household size or composition and social support were not correlated to household food security levels. Researchers affirmed that the tool is valid among London's refugee communities ${ }^{52}$.

In addition, if the primary shopper experienced difficulty with the language and the shopping environment, food insecurity was also increased ${ }^{53}$.

\section{O N CLUSIO N}

The similarity of household food insecurity experiences ranging from worry to adaptations or coping methods in regards to the quantity and quality of food allows for the tool to be easily adjusted to a global audience. Coates et al refer to this global human phenomenon of hunger as the common "core" derived from her analysis of 22 scales in 15 countries $^{54}$. The adaptation of the US developed HFSSM appears to perform well under many circumstances in various regions of the world. However some researchers argue that a ground-up development of household food insecurity measures is essential to accurately capture construct and face validity, or that new scales must be created in each region based on common domains of food insecurity ${ }^{14,54}$. Taking into consideration the resource limitations that most food insecure regions face, it may not be feasible to undergo such in-depth analysis to create a household food insecurity survey. In addition, by creating tools specific to different regions, for example based on local food staples, the usefulness of global comparisons is lost. Sw indale et al. proposes the elimination of coping items from the HFSSM in order to create a generic set of items that can be used universally ${ }^{55}$.

There is still a large amount of research to be conducted in order to have a tool suitable for use in diverse settings across the world and even within countries. As shown in the present review, evidence is gradually accumulating, but the information from outside the United States is still based on recently conducted research. The HFSSM has generated a huge interest throughout the developing world, and was adapted as a national food security tool in some countries 
already. Therefore, it is critical that researchers, policymakers, governmental and non-governmental agencies, and all interested sectors invest time and resources in learning more about the process of developing tools that provide valid and reliable measures of food security. This research composes an essential foundation assuring that food insecurity is confronted with efficient and effective programs.

\section{COLLA BORATORS}

Both of the authors participated in the conceptualization of the manuscript.

\section{REFERE N C E S}

1. Food and Agriculture Organization. The state of food insecurity in the world 2006: Eradicating world hunger - taking stock ten years after the World Food Summit. Rome; 2006.

2. Radimer KL, Olson CM , Campbell CC. Development of indicators to assess hunger. J Nutr. 1990; 120(11):1544-8.

3. Frongillo EA. Validation of measures of food insecurity and hunger. J Nutr. 1999; 129(2S): 506S-9S.

4. Derrickson JP, Fisher AG, Anderson JE. The core food security module scale measure is valid and reliable when used with Asians and Pacific Islanders. J Nutr. 2000; 130(11):2666-74.

5. Kaiser $L L$, Melgar-Quiñonez $\mathrm{HR}$, Lamp $\mathrm{CL}$, Johns MC, Sutherlin JM, Harwood JO. Food security and nutritional outcomes of preschool-age MexicanAmerican children. J Am Diet Assoc. 2002; 102(7): 924-9.

6. Lorenzana PA, Mercado C. Measuring household food security in poor Venezuelan households. Public Health Nutr. 2002; 5(6A):851-7.

7. Melgar-Quinonez $H$, Zubieta $A C$, Valdez $E$, Whitelaw B, Kaiser $L$. Validation of an instrument to monitor food insecurity in Sierra de Manantlan, Jalisco. Salud Publica Mex. 2005; $47(6): 413-22$.

8. Pérez-Escamilla R, Segall-Corrêa AM, Kurdian Maranha L, Archanjo Sampaio MF, Marin-Leon L, Panigassi G. An adapted version of the U.S. Department of Agriculture Food Insecurity module is a valid tool for assessing household food insecurity in Campinas, Brazil. J Nutr. 2004; 134(8):1923-8.
9. Álvarez MC, Estrada A, Montoya EC, MelgarQuiñonez $\mathrm{H}$. Validación de escala de percepción de la seguridad alimentaria doméstica en Antioquia, Colombia. Salud Publica Mex. 2006; 48(6):474-81.

10.Gulliford MC, Nunes C, Rocke B. The 18 Household Food Security Survey items provide valid food security classifications for adults and children in the Caribbean. BM C Public Health. 2006; 8;6(1): 263.

11. Studdert LJ, Frongillo EA Jr, Valois P. Household food insecurity was prevalent in Java during Indonesia's economic crisis. J Nutr. 2001; 131(10): 2685-91.

12. Welch KJ, Mock N, Netrebenko O. Measuring hunger in the Russian Federation using the Radimer/Cornell hunger scale. Bull World Health Organ. 1998; 76(2):143-8.

13. Frongillo EA, Chowdhury N, Ekstrom EC, Naved RT. Understanding the experience of household food insecurity in rural Bangladesh leads to a measure different from that used in other countries. J Nutr. 2003; 133(12):4158-62.

14. Frongillo EA, Nanama S. Development and validation of an experience-based measure of household food insecurity within and across seasons in Northern Burkina Faso. J Nutr. 2006; 136(5):1409S-19S.

15. Coates J, Wilde PE, Webb P, Rogers BL, Houser RF. Comparison of a qualitative and a quantitative approach to developing a household food insecurity scale for Bangladesh. J Nutr. 2006; 136(5):1420S-30S.

16. Nord M, Andrews M, Winicki J. Frequency and duration of food insecurity and hunger in US households. J Nutr Educ Behav. 2002; 34(4): 194-200.

17. Rose D, Habicht JP, Devaney B. Household participation in the Food Stamp and WIC programs increases the nutrient intakes of preschool children. J Nutr. 1998; 128(3):548-55.

18. Alaimo K, Briefel RR, Frongillo EA Jr, Olson CM. Food insufficiency exists in the United States: results from the third National Health and Nutrition Examination Survey (NHANES III). Am J Public Health. 1998; 88(3):419-26.

19. Position of the American Dietetic Association: Addressing world hunger, malnutrition, and food insecurity. J Am Diet Assoc. 2003; 103(8):1046-57.

20. Coates J, Webb P, Houser R. Measuring food insecurity: going beyond indicators of income and anthropometry. Food and nutrition technical assistance project; academy for educational development. Washington; 2003. 
21. Anderson SA. Core indicators of nutritional state for difficult-to-sample populations. J Nutr. 1990; 121(11S):1559-600.

22. Wehler CA, Scott RI, Anderson JJ. The community childhood identification project: a model of domestic hunger-Demonstration project in Seattle, Washington. J Nutr Educ.1992; 24(1):29S-35S.

23. Nord M, Andrews M, Carlson S. Household Food Security in the United States; 2005 [cited 2006 Nov]. Available from: <http://www.ers.usda.gov/ publications/err29/>.

24. Kempson K, Keenan DP, Sadani PS, Adler A. $M$ aintaining food sufficiency: Coping strategies identified by limited-resource individuals versus nutrition educators. J Nutr Educ Behav. 2003; 35(4):179-88

25. Hamelin AM, Beaudry M, Baict JP. Characterization of food insecurity in Quebec: food and feelings. Soc Sci Med. 2002; 54(1):119-32.

26. Olson CM. Nutrition and health outcomes associated with food insecurity and hunger. J Nutr. 1999; 129(2S):517S-20S.

27. Dixon LB, Winkleby MA, Radimer KL. Dietary intakes and serum nutrients differ between adults from food-insufficient and food-sufficient families: third national health and nutrition examination survey, 1988-1994. J Nutr. 2001; 131(4):1232-46.

28. Oh SY, Hong MJ. Food insecurity is associated with dietary intake and body size of Korean children from low-income families in urban areas. Eur J Clin Nutr. 2003; 57(12):1598-604.

29. Matheson DM, Varady J, Varady A, Killen JD. Household food security and nutritional status of Hispanic children in the fifth grade. Am J Clin Nutr. 2002; 76(1):210-7.

30. Vozoris NT, Tarasuk VS. The health of Canadians on welfare. Can J Public Health. 2004 95(2): 115-20.

31. Hackett $M$, Melgar-Quiñonez $H$, Zubieta $A C$, Hernandez K. Food Security and Household Food Supplies in Rural Ecuador. Arch Latinoam Nutr. 2007; 57(1):10-7

32. Parás P, Pérez-Escamilla R. El rostro de la pobreza: la inseguridad alimentaria en el Distrito Federal. Rev Este País. 2004; 158(5):45-50.

33. Melgar-Quinonez HR, Zubieta AC, MkNelly B, Nteziyaremye A, Gerardo MF, Dunford C. Household food insecurity and food expenditure in Bolivia, Burkina Faso, and the Philippines. J Nutr. 2006; 136(5):1431S-7S.

34. Fiszbein A, Giovagnoli I. Hambre en Argentina. [cited 2003 Jun]. Available from: <http://www. undp-povertycentre.org/publications/health/food-
security-nutrition/Hambre_en_Argentina-FiszbeinJun03.pdf>.

35. Marin-Leon L, Segal-Corrêa AM, Panigassi G, M aranha LK, Sampaio MF, Pérez-Escamilla R. Food insecurity, perception in families with elderly in Campinas, Sao Paulo, Brazil. Cad Saúde Publica. 2005; 21(5):1433-40.

36. Rivera-Márquez JA, Guerrero-Alcocer EV. Inseguridad alimentaria en ancianos pobres de la Ciudad de México: importancia para la salud pública y para la agenda social. Nutr Clin. 2006; 9(2):13-9.

37. Brasil. Ministério do Desenvolvimento Social e Combate à Fome. Ministério do Planejamento, Orçamento e Gestão; 2006. Pesquisa Nacional por Amostra de Domicilios; Segurança A limentar; 2004 [acesso 2008 maio 27]. Disponível em: <http://www.ibge.gov.br/home/estatistica/ populacao/trabalhoerendimento/pnad2004/ default.shtm>.

38. Melgar-Quinonez HR, Nord M, Pérez-Escamilla R, Segall-Corrêa AM. Psychometric properties of a modified US-household food security survey module in Campinas, Brazil. Eur J Clin Nutr. 2008; 62(5):665-73.

39. Hackett M, Melgar-Quinonez HR, Pérez-Escamilla R, Segall-Corrêa AM. Gender of respondent does not affect the psychometric properties of the Brazilian household food security scale. Int J Epidemiol. 2008; [Advance online publication, May 2008]; doi: 10.1093/ije/dyn084.

40. Hackett M, Melgar-Quiñonez $H$, Alvarez Uribe MC. Internal validity of a household food security scale is consistent among diverse populations participating in a food supplement program in Colombia. BMC Public Health. [Advance online publication, May 2008]; doi: 10.1186/1471-2458-8-175.

41. Gulliford MC, Mahabir D, Rocke B. Food insecurity, food choices, and body mass index in adults: nutrition transition in Trinidad and Tobago. Int J Epidemiol. 2003; 32(4):508-32.

42. M clntyre L, Glanville NT, Officer S, Anderson B, Raine KD, Dayle JB. Food insecurity of low-income lone mothers and their children in Atlantic Canada. Can J Public Health. 2002; 93(6):411-5.

43. Tarasuk VS. Household food insecurity with hunger is associated with women's food intakes, health and household circumstances. J Nutr. 2001; 131(10):2670-6.

44. Kendall A, Olson CM, Frongillo EA Jr. Validation of the Radimer/Cornell measures of hunger and food insecurity. J Nutr. 1995; 125(11):2793-801. 
45. Piaseu N, Mitchell P. Household food insecurity among urban poor in Thailand. J Nurs Scholarsh. 2004; 36(2):115-21.

46. Hamelin AM, Habicht JP, Beaudry M. Food insecurity: consequences for the household and broader social implications. J Nutr. 1999; 129(2S): 525S-8S.

47. Renzaho AM. Food insecurity, malnutrition and mortality in Maewo and Ambae Islands, Vanuatu. Public Health Nutr. 2006; 9(6):798-807.

48. Oh SY, Hong MJ. Food insecurity is associated with dietary intake and body size of Korean children from low-income families in urban areas. Eur J Clin Nutr. 2003; 57(12):1598-604.

49. Oldewage-Theron WH, Dicks EG, Napier CE. Poverty, household food insecurity and nutrition: coping strategies in an informal settlement in the Vaal Triangle, South Africa. Public Health. 2006; 120(9):795-804.

50. Hadley C, Patil CL. Food insecurity in rural Tanzania is associated with maternal anxiety and depression. Am J Hum Biol. 2006; 18(3):359-68.

51. Tingay RS, Tan CJ, Tan NC, Tang S, Teoh PF, Wong $R$, et al. Food insecurity and low income in an
English inner city. J Public Health M ed. 2003; 25(2): 156-9.

52. Sellen DW, Tedstone AE, Frize J. Food insecurity among refugee families in East London: results of a pilot assessment. Public Health Nutr. 2002; 5(5): 637-44.

53. Hadley C, Sellen D. Food security and child hunger among recently resettled Liberian refugees and asylum seekers: a pilot study. J Immigr Minor Health. 2006; 8(4):369-75.

54. Coates J, Frongillo EA, Rogers BL, Webb P, Wilde $\mathrm{PE}$, Houser R. Commonalities in the experience of household food insecurity across cultures: what are measures missing? J Nutr. 2006; 136(5): 1438S-48S.

55. Swindale A, Bilinsky P. Development of a universally applicable household food insecurity measurement tool: process, current status, and outstanding issues. J Nutr. 2006; 136(5): 1449S-52S.
Received on: 1/3/2007

Final resubmitted on: 14/8/2007

Approved on: 8/5/2008 
